\title{
Frequency and Factors Associated with Depression during Chronic Lumbosciatica in Sub-Saharan African Black Patients
}

\author{
Charles Sougué1,2* ${ }^{(1)}$, Joëlle W. S. Tiendrébeogo', Fulgence Kaboré1, Enselme Y. Zongo1, \\ Nicole D. B. Ahongbonon1, Camille Sompougdou1,3, Yirozounlomian Tiaho4, \\ Dieu-Donné Ouédraogo ${ }^{1}$ \\ ${ }^{1}$ Department of Rheumatology, University Hospital Center of Bogodogo, Ouagadougou, Burkina Faso \\ ${ }^{2}$ Department of Internal Medicine, Sourô Sanou University Hospital Center, Bobo Dioulasso, Burkina Faso \\ ${ }^{3}$ Department of Medicine, Regional University Hospital Center of Ouahigouya, Ouahigouya, Burkina Faso \\ ${ }^{4}$ Department of Physical Medicine and Rehabilitation, University Hospital Center of Bogodogo, Ouagadougou, Burkina Faso \\ Email: ^souguecharles@gmail.com
}

How to cite this paper: Sougué, C., Tiendrébeogo, J.W.S., Kaboré, F., Zongo, E.Y., Ahongbonon, N.D.B., Sompougdou, C., Tiaho, Y. and Ouédraogo, D.-D. (2020) Frequency and Factors Associated with Depression during Chronic Lumbosciatica in Sub-Saharan African Black Patients. Open Journal of Rheumatology and Autoimmune Diseases, 10, 157-163. https://doi.org/10.4236/ojra.2020.104017

Received: November 3, 2020

Accepted: November 27, 2020

Published: November 30, 2020

Copyright (c) 2020 by author(s) and Scientific Research Publishing Inc. This work is licensed under the Creative Commons Attribution International License (CC BY 4.0).

http://creativecommons.org/licenses/by/4.0/ (c) (i) Open Access

\begin{abstract}
Objective: This study was focused on depression rate and associated factors in chronic lumbosciatica in sub-Saharan African black patients. Patients and Methods: We conducted a prospective descriptive and analytical study in chronic lumbosciatica cases seen in rheumatology/internal medicine, neurology and neurosurgery departement at the Yalgado ouédraogo University Hospital Center from April 31, 2016 to July 31, 2016. The diagnosis of depression was based on Hamilton scale. Its frequency was evaluated and the associated factors were analyzed. Results: One hundred and forty-nine patients were included in the study. Their average age was 49.5 years and the sex ratio was 0.42 (44 men/105 women). Thirty-eight patients lived alone (25.5\%). Pain intensity was severe in 46 patients (30.9\%) and moderate in 77 patients $(51.7 \%)$. Neuropathic pain was present in 108 patients $(72.5 \%)$. One hundred and ten patients had depression (73.8\%). Depression was severe in 38 patients (25.5\%), moderate in 35 patients (23.5\%), and mild in 37 patients (24.8\%). Factors associated with depression were living alone (Odds-Ratio 3.5), high (Odds-Ratio 11.1) or moderate (Odds-Ratio 5.9) intensity of pain, and the presence of neuropathic pain (Odds-Ratio 2.5). Conclusion: Depression was frequent during chronic lumbosciatica in sub-Saharan African black patients. Its associated factors were living alone, presence of moderate or severe pain, and neuropathic pain.
\end{abstract}

\section{Keywords}

Depression, Lumbosciatica, Africa, Burkina Faso 


\section{Introduction}

Chronic lumbosciatica is a frequent reason for consultation in rheumatology [1] [2] [3] [4]. Depending on studies, the prevalence of lumbosciatica varies between $1.2 \%$ and $61.7 \%$ [1] [2] [3] [4]. In Africa, its prevalence varies between $8.3 \%$ and $61.7 \%$ and would be between $56.4 \%$ and $61.7 \%$ in Burkina Faso [2] [3] [4]. Chronic lumbosciatica is difficult to manage [1] [2] [3] [4]. Its chronic nature could lead to an association of other factors that could maintain chronicity [5]-[10]. Some studies have investigated factors associated with lumbosciatica [5]-[10]. According to a meta-analysis, advanced age, smoking, physical stress of spine and psychological stress such as depression are risk factors of poor prognostic in chronic lumbosciatica [10]. Some western studies have analyzed the association of depression with lumbosciatica [5]-[13]. Female sex, being 50 - 64 years of age, low socioeconomic status and low social support increased the likelihood of comorbid depression and chronic lumbosciatica [10] [11]. This work aims to study the frequency and factors associated with depression during chronic lumbosciatica in a sub-Saharan African black population.

\section{Patients and Methods}

We conducted a prospective descriptive and analytical study over a period of three months from April 31, 2016 to July 31, 2016 on patients with chronic lumbosciatica. They were patients from sub-Saharan Africa seen in the rheumatology/internal medicine, neurology and neurosurgery department at the Yalgado Ouédraogo University Hospital in Burkina Faso. We included patients aged 18 years or older with chronic sciatica who had agreed to participate in the study. Patients lost in follow-up, and those we were unable to examine, were excluded from the study.

The diagnosis of chronic lumbosciatica was made on the basis of clinical, laboratory and radiological examination. Chronic lumbosciatica was defined as any lumbar spinal pain with degenerative origin, with irradiation in pelvic limbs, which has been evolving for more than three months. All patients underwent a standard radiography of lumbar spine. For patients who may have confusing standard radiography images, we performed a scanner or magnetic resonance imaging in order to rule out infectious, rheumatic, or tumor spondylodiscitis. No patient had clinical or radiographic sacroiliitis. Blood count, sedimentation rate and $\mathrm{C}$ reactive protein were systematic; no patient had a biological inflammatory syndrome.

We performed a clinical examination on all patients and collected their epidemiologic and clinical characteristics, and their depressive state. The epidemiologic characteristics of the patients that were studied were: age, sex, marital status, profession, level of education, body mass index (BMI). The clinical aspects of chronic sciatica studied were: duration of evolution, type of sciatica pain, visual analogue scale (VAS), neuropathic nature of pain according to the DN4 questionnaire [14]. The depressive state of patients was evaluated accord- 
ing to the Hamilton scale [15]. The frequency of depression was evaluated and the associated factors were analyzed by the "EPI-INFO" software in its version 7. The significance level during the statistical tests was fixed at $5 \%$. Variables were compared using the Chi 2 test with a 95\% confidence interval. The evaluation of odds ratio (OR) has been made to highlight the risks associated with a $95 \%$ confidence interval and to evaluate their importance. The variable was considered a risk factor if $\mathrm{OR}>1$. From an ethical standpoint, patients' privacy and confidentiality were respected, and their oral and written consent was required.

\section{Results}

One hundred and forty-nine patients were included in the study. The mean age of the study population was 49.5 years \pm 13.4 with extremes of 18 and 81 years. The sex ratio was 0.42 (44 men/105 women).

Regarding marital status, one hundred and eleven patients (74.5\%) lived as a couple and 38 patients (25.5\%) lived alone. In terms of profession, 48 patients (32.2\%) were housewives, 44 (29.5\%) patients were formal sector workers, 54 patients (36.3\%) were informal sector workers, and three patients (2\%) were students. In terms of education level, 66 patients (44.3\%) were out of school. Twenty-seven patients (18.1\%) had primary study level, 40 patients $(26.9 \%)$ had secondary study level, and 16 patients (10.7\%) had higher study level.

The mean BMI of the patients was $27.4 \mathrm{Kg} / \mathrm{m}^{2} \pm 7.4$ with extremes of 13.4 and 46.8. Sixty patients $(40.2 \%)$ had a normal BMI, 49 patients (32.9\%) were overweight, and 40 patients $(26.9 \%)$ were obese. The medical history observed was hypertension in 19 patients (12.8\%), a history of a lumbar spinal trauma in 27 patients (18.1\%), and a history of lumbar spine surgery in seven patients (4.7\%).

For pain, the average visual analogue scale (VAS) was 6.4/10. The intensity of pain was considered to be severe (VAS > 6/10) in 46 patients $(30.9 \%)$, moderate (VAS between 4 and 6/10) in 77 patients (51.7\%), and mild (VAS between 0 and $3 / 10)$ in 26 patients (17.4\%).

The mean duration of symptomatology was 58.9 months, with a duration of more than 12 months in 132 patients (88.6\%). Neuropathic pain was observed in 108 patients (72.5\%). S1 sciatica was observed in 79 patients (53\%), L5 sciatica in 68 patients (45.7\%), and L4 cruralgia in two patients (1.3\%).

Depression was present in 110 patients (73.8\%). It was severe in 38 patients (25.5\%), moderate in 35 patients (23.5\%), and mild in 37 patients $(24.8 \%)$. Factors associated with depression were living alone (Odds-Ratio 3.5), high (Odds-Ratio 11.1) or moderate (Odds-Ratio 5.9) intensity of pain, and the presence of neuropathic pain (Odds-Ratio 2.5). Table 1 represents the statistical relationship between the factors studied and depression. Table 2 represents the factors associated with depression according to a multivariate analysis.

\section{Discussion}

The frequency of depression was $73.8 \%$ in sub-Saharan African black patients 
Table 1. Distribution of statistical relationships between factors studied and depression in patients with chronic lumbosciatica.

\begin{tabular}{|c|c|c|c|c|}
\hline & & With depression (\%) & Without depression (\%) & $p$ value \\
\hline \multirow[b]{2}{*}{ Age (Years) } & $\leq 49$ & $57(75 \%)$ & $19(25 \%)$ & \multirow[b]{2}{*}{0.739} \\
\hline & $>49$ & $53(72.6 \%)$ & $20(27.5 \%)$ & \\
\hline \multirow[b]{2}{*}{ Sex } & Female & $80(76.2 \%)$ & $25(23.8 \%)$ & \multirow[b]{2}{*}{0.310} \\
\hline & Male & $30(68.2 \%)$ & $14(31.8 \%)$ & \\
\hline \multirow{4}{*}{ Level of study } & Unschooled & $50(75.8 \%)$ & $16(24.2 \%)$ & \multirow{4}{*}{0.5509} \\
\hline & Primary & $22(81.5 \%)$ & $5(18.5 \%)$ & \\
\hline & Secondary & $28(70 \%)$ & $12(30 \%)$ & \\
\hline & Superior & $10(62.5 \%)$ & $6(37.5 \%)$ & \\
\hline \multirow{2}{*}{ Marital status } & Living in couple & $77(69.4 \%)$ & $34(30.6 \%)$ & \multirow{2}{*}{0.034} \\
\hline & Living alone & $33(86.4 \%)$ & $5(13.2 \%)$ & \\
\hline \multirow{3}{*}{ Pain intensity } & Severe & $43(93.5 \%)$ & $3(6.5 \%)$ & \multirow{3}{*}{0.0005} \\
\hline & Moderate & $53(68.8 \%)$ & $24(31.2 \%)$ & \\
\hline & Mild & $14(53.8 \%)$ & $12(46.2 \%)$ & \\
\hline \multirow{2}{*}{$\begin{array}{c}\text { Duration of } \\
\text { symptomatology }\end{array}$} & $\geq 1$ an & $94(71.2 \%)$ & $38(28.8 \%)$ & \multirow{2}{*}{0.075} \\
\hline & $<1$ an & $16(94.1 \%)$ & $1(5.9 \%)$ & \\
\hline \multirow{2}{*}{ Neuropathic pain } & Yes & $86(79.6 \%)$ & $22(20.4 \%)$ & \multirow{2}{*}{0.008} \\
\hline & No & $24(58.5 \%)$ & $17(41.5 \%)$ & \\
\hline
\end{tabular}

Table 2. distribution of factors associated with depression in patients with chronic lumbosciatica according to multivariate analysis.

\begin{tabular}{cccc}
\hline & Odds Ratio & IC 95\% & $p$ value \\
\hline Severe pain & 11.1 & {$[2.7-50]$} & 0.001 \\
Moderate pain & 5.9 & {$[1.6-20]$} & 0.008 \\
Live alone (not in a relationship) & 3.5 & {$[1.1-10]$} & 0.030 \\
Presence of neuropathic pain & 2.5 & {$[1.17-5.99]$} & 0.045 \\
\hline
\end{tabular}

with depression during chronic lumbosciatica. Its risk factors were living alone, having moderate or severe pain, or neuropathic type pain.

The epidemiological and clinical characteristics of the study population corroborate other African studies [2] [3] [4]. The lumbar spine of black African people has some peculiarities [3] [16]. There is an increase of physiological lumbar lordosis, which could be a risk factor for lumbosciatica [3] [16].

The frequency of depression appears to be high in lumbosciatica in most studies [5]-[13]. Lumbosciatica has been suggested by some authors as a risk factor for depression, anxiety and psychosomatic symptoms [17]. The risk of self-harm or suicide can be as high as $51.4 \%$ in depressed low back pain patients [17]. For other authors, depression is also a risk factor for sciatica [18]. The risk of developing lumbosciatica is four times higher in depressed patients [18]. The pres- 
ence of depression during chronic sciatica could therefore constitute a vicious circle with these two self-inducing pathologies leading to chronicity and an unfavorable evolution. Indeed, a meta-analysis concluded that depression is a factor of poor prognosis during lumbosciatica [10].

In our study, the high intensity of pain related to chronic sciatica could increase the risk of depression five to eleven times. The chronic, hyperalgesic and disabling nature of lumbosciatica could promote the onset of catastrophizing, a sedentary lifestyle with physical and psychosocial deconditioning leading to anxiety and depression [19] [20]. According to some authors, catastrophizing is one of the major psychological mechanisms of the onset of depression, and exacerbation of pre-existing depression in the context of musculoskeletal pain [19].

In the literature, neuropathic pain is associated with the occurrence of impairment in quality of life with anxiety and depression [9]. It increased the risk of developing depression 2.5 times in our study. Neuropathic pain is characterized by the simultaneous presence of several types of pain [14]. This painful sensation which is sometimes difficult to explain by the patient, can be hyperalgesic, debilitating, with a chronic evolution. This could cause a physical and psycho-social deconditioning syndrome with catastrophizing, and lead to anxiety and depression [14] [19] [20].

According to a recent meta-analysis, loneliness and social isolation are significantly associated with the onset of psychological disorders including anxiety and depression [21]. Living alone increased the risk of depression 3.5 times in a patient with chronic lumbosciatica in our study. According to some authors, the poor psychosocial support often seen during loneliness could explain the onset of depression [10] [11]. However, a recent study concluded that Self-disgust would be the major psychological mechanism for the onset of depression during loneliness [22]. Chronic lumbosciatica in itself is a risk factor for depression according to some authors, so its association with loneliness could initiate or exacerbate a pre-existing depression [17] [21].

\section{Conclusion}

This study was focused on depression rate and associated factors in chronic lumbosciatica in sub-Saharan African black patients. Most of the studies that have studied this association are Western. The lumbar spine of black African people has some peculiarities. This study brings new elements to the association of depression and chronic lumbosciatica in black patients from sub-Saharan Africa. We found that depression was frequent during chronic lumbosciatica in sub-Saharan African black patients. Its associated factors were living alone, moderate or severe pain, and the presence of neuropathic pain. Depression can be the cause and/or consequence of chronic lumbosciatica. However, the presence of depression is a poor prognostic factor during chronic lumbosciatica. It is important to take effective care of acute lumbosciatica in order to avoid chronicity. The nociceptive and neuropathic pain of chronic lumbosciatica must also be 
effectively treated while providing psychosocial management to prevent the onset of depression.

\section{Conflicts of Interest}

The authors declare that they have no links of interest.

\section{References}

[1] Konstantinou, K. and Dunn, K.M. (2008) Sciatica: Review of Epidemiological Studies and Prevalence Estimates. Spine, 33, 2464-2672.

https://doi.org/10.1097/BRS.0b013e318183a4a2

[2] Millogo, A., Bamouni, A.Y., Taoko, A., Ki-Zerbo, G.A., Sawadogo, A.B., Yameogo, A. and Durand, G. (1999) Lombosciatiques: Profil radioclinique et étiologique au centre hospitalier de Bobo-Dioulasso (Burkina Faso). Médecine d Afrique Noire, 46, 375-378.

[3] Ouédraogo, D.D., Ouédraogo, V., Ouédraogo, L.T., Kinda, M., Tieno, H., Zoungrana, E.I. and Drabo, J.Y. (2010) Prévalence et facteurs de risque associés à la lombalgie chez le personnel hospitalier à Ouagadougou (Burkina Faso). Médecine Tropicale, 70, 277-280.

[4] Gandema, S., Cessouma, K.R., Dakouré, W.P. and Nacro, B. (2012) Profil épidémiologique du handicap physique au Burkina Faso. Médecine d Afrique Noire, 59, 542-547.

[5] Fjeld, O., Grotle, M., Siewers, V., Pedersen, L.M., Nilsen, K.B. and Zwart, J.A. (2017) Prognostic Factors for Persistent Leg-Pain in Patients Hospitalized with Acute Sciatica. Spine, 42, 272-279. https://doi.org/10.1097/BRS.0000000000001773

[6] Konstantinou, K., Dunn, K.M., Ogollah, R., Lewis, M., van der Windt, D. and Hay, E.M. (2018) Prognosis of Sciatica and Back-Related Leg Pain in Primary Care: The ATLAS Cohort. The Spine Journal, 18, 1030-1040. https://doi.org/10.1016/j.spinee.2017.10.071

[7] Parreira, P., Maher, C., Steffens, D., Hancock, M. and Ferreira, M. (2018) Risk Factors for Low Back Pain and Sciatica: An Umbrella Review. The Spine Journal, 18, 1715-1721. https://doi.org/10.1016/j.spinee.2018.05.018

[8] Uher, T. and Bob, P. (2013) Neuropathic Pain, Depressive Symptoms, and C-Reactive Protein in Sciatica Patients. International Journal of Neuroscience, 123, 204-208. https://doi.org/10.3109/00207454.2012.746335

[9] Tutoglu, A., Boyaci, A., Karababa, I.F., Koca, I., Kaya, E., Kucuk, A. and Yetisgin, A. (2015) Psychological Defensive Profile of Sciatica Patients with Neuropathic Pain and Its Relationship to Quality of Life. Zeitschrift für Rheumatologie, 74, 646-651. https://doi.org/10.1007/s00393-014-1527-4

[10] Martini, L. and Hoffmann, F. (2018) Comorbidity of Chronic Back Pain and Depression in Germany: Results from the GEDA Study, 2009 and 2010. Zeitschrift für Evidenz, Fortbildung und Qualität im Gesundheitswesen, 137, 62-68. https://doi.org/10.1016/j.zefq.2018.10.003

[11] Tsuji, T., Matsudaira, K., Sato, H. and Vietri, J. (2016) The Impact of Depression among Chronic Low Back Pain Patients in Japan. BMC Musculoskeletal Disorders, 17, 447. https://doi.org/10.1186/s12891-016-1304-4

[12] Pinheiro, M.B., Ferreira, M.L., Refshauge, K., Maher, C.G., Ordoñana, J.R., Andrade, T.B. and Ferreira, P.H. (2016) Symptoms of Depression as a Prognostic Factor for Low Back Pain: A Systematic Review. The Spine Journal, 16, 105-116. 
https://doi.org/10.1016/j.spinee.2015.10.037

[13] Marshall, P.W., Schabrun, S. and Knox, M.F. (2017) Physical Activity and the Mediating Effect of Fear, Depression, Anxiety, and Catastrophizing on Pain Related Disability in People with Chronic Low Back Pain. PLoS ONE, 12, e0180788. https://doi.org/10.1371/journal.pone.0180788

[14] Bouhassira, D. (2005) Le questionnaire DN4: Le nouvel outil d'aide au diagnostic des douleurs neuropathiques. Douleurs. Evaluation-Diagnostic-Traitement, 6, 297-300. https://doi.org/10.1016/S1624-5687(05)80288-4

[15] Hamilton, M. (1960) A Rating Scale for Depression. Journal of Neurology, Neurosurgery, and Psychiatry, 23, 56-62. https://doi.org/10.1136/jnnp.23.1.56

[16] Hanson, P., Magnusson, S.P. and Simonsen, E.B. (1998) Differences in Sacral Angulation and Lumbosacral Curvature in Black and White Young Men and Women. Cells Tissues Organs, 162, 226-231. https://doi.org/10.1159/000046437

[17] Bener, A., Verjee, M., Dafeeah, E.E., et al. (2013) Psychological Factors: Anxiety, Depression, and Somatization Symptoms in Low Back Pain Patients. Journal of Pain Research, 6, 95-101. https://doi.org/10.2147/JPR.S40740

[18] Carroll, L.J., Cassidy, J.D. and Côté, P. (2004) Depression as a Risk Factor for Onset of an Episode of Troublesome Neck and Low Back Pain. Pain, 107, 134-139. https://doi.org/10.1016/j.pain.2003.10.009

[19] Linton, S.J., Nicholas, M.K., MacDonald, S., et al. (2011) The Role of Depression and Catastrophizing in Musculoskeletal Pain. European Journal of Pain, 15, 416-422. https://doi.org/10.1016/j.ejpain.2010.08.009

[20] Dupeyron, A., Coudeyre, E., Gremeaux, V. and Perrey, S. (2014) Les patients lombalgiques chroniques sont-ils vraiment déconditionnés? La Lettre du Rhumatologue, 404, 20-25.

[21] Leigh-Hunt, N., Bagguley, D., Bash, K., et al. (2017) An Overview of Systematic Reviews on the Public Health Consequences of Social Isolation and Loneliness. Public Health, 152, 157-171. https://doi.org/10.1016/j.puhe.2017.07.035

[22] Ypsilanti, A., Lazuras, L., Powell, P. and Overton, P. (2019) Self-Disgust as a Potential Mechanism Explaining the Association between Loneliness and Depression. Journal of Affective Disorders, 243, 108-115. https://doi.org/10.1016/j.jad.2018.09.056 